Ataxia-Telangiectasia. A Cellular and Molecular Link Between Cancer, Neuropathology, and Immune Deficiency

Edited by B A Bridges and D G Harnden. (Pp xix + 400; figures + tables. $£ 20 \cdot 75$.) Chichester, New York: Wiley. 1982.

In essence this book contains papers presented at a workshop held in November 1980, a workshop that appears by these accounts to have been a very exciting meeting. However, the book is more than this, for the editors have asked each author to give a brief review of the work leading up to their research, before presenting their results, and in addition have included six excellent review chapters. The result is that the book has become a monograph and a very stimulating one, concerning one of the most interesting diseases that exists.

Ataxia-telangiectasia (AT) is an important disease to study because as well as being characterised by progressive neurological degeneration and abnormalities in blood vessels and in the immune system (Waldmann, p37), it confers a susceptibility to certain cancers both in the homozygous recessive state (Spector et al, p103) and in the heterozygous state (Swift, p355). This susceptibility could well be related to the increased sensitivity of chromosomes to $\mathrm{X}$ or $\mathrm{Y}$ irradiation (Taylor, p53), to the formation of chromosome clones, and/or to the increased sensitivity of cultured fibroblasts and lymphocytes to $\mathrm{X}$ or $\mathrm{Y}$ irradiation (Lehmann, p83). This latter response has been carefully analysed by Cox (p141), whose experiments show that in AT there is a complete block in the repair of potentially lethal radiation-produced damage at both high and low doses of radiation, and that different AT biochemical phenotypes appear to be equally deficient. The presence of this DNA repair defect would account for the devastating response that AT patients have when given therapeutic radiation for cancer, and further study of their defects will be useful in the future understanding of normal persons' responses to radiation. The abnormal response of blood and skin cells to irradiation also enables antenatal diagnosis of the condition in at least some cases and this is discussed by Gianelli et al (p393).

The sites at which chromosome breaks and rearrangements occur are not random and those particularly involved are $7 \mathrm{p} 14,7 \mathrm{q} 35,14 \mathrm{q} 12$, and 14q32 (Hecht and Kaiser-McCaw, p235; O'Connor et al, p259). This raises the possibility that one of these sites either represents the position of the recessive AT gene or of other genes concerned with carcinogenesis or immune deficiency.

There is a further puzzle about AT which emerges from this book. Paterson et al (p271) and Inoue et al (p305) describe how cultured hybridised cells from different patients may 'complement' or 'make good' the DNA repair defects that are present in either when cultured alone. Several different complementation groups, based on such hybridisation experiments, exist for AT which suggest that there are different genes for AT, situated at different loci: indeed it is difficult to think of an alternative explanation for these laboratory findings. However, this hypothesis is not compatible with the population findings. As Hecht and Kaiser-McCaw (p197) observe, the consanguinity rate in AT is low, too low indeed for a rare condition that really consists of several even rarer entities. The commonly quoted estimate of the frequency of AT is based on its prevalence in Los Angeles school children and gives a figure of about 1 in 40000 . The observed consanguinity rate of about $3 \%$ is just compatible with this, but not with the suggestion that AT consists of several rarer entities caused by non-allelic genes. It would be useful if a further prevalence study could be carried out.

In summary, this book gives a comprehensive account of a disease that is important because of what it can teach about carcinogenesis, neurological degeneration, and immune deficiency. It should serve as a basis for future research ideas and actions. I can recommend it not only to those clinicians and scientists who know one aspect of AT, or a little of all aspects, but also to those who are unfamiliar with the subject.

S BUNDEY

\section{Heritable Disorders of Connective Tissue}

American Academy of Orthopedic Surgeons Symposium, San Diego, California, 1980. Edited by W H Akeson, P Bornstein, and J Glimcher. (Pp xiv + 380; 193 figures + tables. £43.50.) St Louis, Toronto, London: Mosby. 1982.

These are the beautifully produced proceedings of a symposium held in 1980 and published in 1982 . It contains a very adequate summary of the molecular biology and protein chemistry of the inherited defects of collagen, but also includes much useful 